\title{
High dose rate endobronchial brachytherapy: results and complications in 189 patients
}

\author{
M. Taulelle, B. Chauvet, P. Vincent, C. Félix-Faure, B. Buciarelli, R. Garcia, Y. Brewer, F. Reboul
}

High dose rate endobronchial brachytherapy: results and complications in 189 patients. M. Taulelle, B. Chauvet, P. Vincent, C. Félix-Faure, B. Buciarelli, R. Garcia, Y. Brewer, F. Reboul. CERS Journals Ltd 1998.

ABSTRACT: The purpose of this study was to determine the benefit of high dose rate endobronchial brachytherapy in the treatment of obstructive lung cancer.

Between September 1990 and March 1995, 189 patients with bronchogenic carcinoma were treated with high dose rate endobronchial brachytherapy. Most patients $(69.3 \%)$ had received prior treatment and presented with symptomatic bronchial obstruction due to either recurrent or residual endobronchial disease. A small group $(\mathbf{1 2 \%})$ was medically unfit for either surgical resection or thoracic radiotherapy and benefited from endobronchial brachytherapy alone for small endobronchial tumours. The remainder of the patients had not been treated previously and endobronchial brachytherapy was performed for life-threatening symptoms requiring emergency obstruction relief before other therapy. Treatment was performed weekly and consisted of three to four 8 to $10 \mathrm{~Gy}$ fractions at a radius of $10 \mathrm{~mm}$ from the centre of the source.

Major symptomatic relief was obtained for haemoptysis (74\%), dyspnoea (54\%), and cough $(54 \%)$. Complete endoscopic response was observed in $54 \%$ of cases. Median survival was 7 months for the entire group. For small, strictly endobronchial tumours, complete response rate was $96 \%$, median survival 17 months, and 30 month survival 46\%, with a plateau starting at 18 months. Grade 3 to 4 toxicities occurred at a rate of $17 \%$ and included massive haemoptysis $(n=13)$, bronchial stenosis $(n=12)$, soft tissue necrosis $(n=8)$, and bronchial fistula $(n=3)$. By univariate analysis, no factor was found to be predictive of late pulmonary toxicity.

The present study confirms the usefulness of endobronchial brachytherapy in alleviating symptoms caused by endobronchial recurrence of bronchogenic carcinoma. In addition, this therapy can be tried with curative intent in patients who present with small endobronchial tumours and are not candidates for other forms of therapy. Eur Respir J 1998; 11: 162-168.
Dept of Radiation Therapy, Clinique Sainte Catherine, Avignon, France.

Correspondence: M. Taulelle

Radiation Therapy Dept

Clinique Sainte Catherine

B.P. 846

84082 Avignon

France

Fax: 00334902761180

Keywords: Endobronchial brachytherapy high dose rate radiotherapy

lung cancer

Received: March 281997

Accepted after revision September 271997
Lung cancer is the most common cause of death by cancer, and its prognosis is dismal in patients who present with locally advanced disease that is surgically unresectable. Besides improving overall long-term survival, one should aim to develop techniques that will improve quality of life in the course of the disease. Between 30 and $40 \%$ of the patients will present with symptoms related to the endobronchial component of their tumour, namely, cough, haemoptysis, shortness of breath, and post-obstructive atelectasis with infection. Until recently, the most common technologies used in these situations were laser photoresection and cryotherapy. There is now increasing interest in the use of high dose rate endobronchial brachytherapy to alleviate symptoms of endobronchial bronchogenic carcinoma. This procedure has been used in the treatment of stenosing endobronchial recurrence, as part of the initial treatment of large obstructive lesions, or with curative intent in medically inoperable patients present-ing with small strictly endobronchial tumours. Since 1990, we have used endobronchial brachytherapy in all of these clinical settings and will present here the results of our experience both in terms of effectiveness and toxicity.

Materials and methods

\section{Study subjects}

Between September 1990 and March 1995, 189 patients with lung cancer were treated in our institution with high dose rate endobronchial brachytherapy. Patient characteristics are presented in table 1 . The vast majority $(90 \%)$ presented with symptoms of endobronchial disease and over half had a poor performance status equal to or greater than $2(53 \%)$ according to the World Health Organization scale. Main symptoms were cough $(82 \%)$, dyspnoea $(71 \%)$, and haemoptysis $(36 \%)$. The tumour was located in the upper lobe in $36 \%$ of the cases, the lower lobe in $26 \%$, the mainstem bronchus in $23 \%$, and in the trachea or at the level of the carina in $6 \%$. In 11 patients, two or three endobronchial tumours were present 
Table 1. - Patient characteristics

\begin{tabular}{lc}
\hline Characteristics & \\
\hline Median age yrs (range) & $68(34-93)$ \\
Sex male/female & $171 / 18$ \\
Histology n & \\
Squamous cell & 158 \\
Adenocarcinoma & 14 \\
Small cell & 12 \\
Undifferentiated large cell & 5 \\
Clinical stage n & \\
Stage I & 56 \\
Stage II & 17 \\
Stage IIIA & 62 \\
Stage IIIB & 29 \\
Stage IV & 13 \\
Anatomical location n & \\
Trachea/carina & 11 \\
Mainstem bronchus & 42 \\
Upper lobe & 69 \\
Lower lobe & 49 \\
Percentage of bronchial obstruction n & \\
100\% & 47 \\
$75 \%$ & 67 \\
$50 \%$ & 30 \\
$25 \%$ & 25 \\
None & 17 \\
\hline
\end{tabular}

simultaneously. Most tumours had a squamous cell histology $(84 \%)$. The percentages of bronchial obstruction (Score of Kohek [1]) are presented in table 1. Ninety one patients $(51 \%)$ presented with extrapulmonary disease that was either limited to the mediastinal lymph nodes $(n=72)$, or metastatic extrathoracic $(n=4)$, or both. In pretreated patients, previous therapies included surgery in 46 cases (24\%), chemotherapy in $82(43 \%)$, and radiotherapy in $117(62 \%)$. Median prior external thoracic radiation dose was 60 Gy. In 56 patients (30\%), endobronchial brachytherapy was used as part of the primary treatment of the tumour. Of these patients, 48 had benefited from either initial laser photoresection $(\mathrm{n}=27)$, or initial cryotherapy $(n=7)$, or both $(n=14)$. The remainder of the patients $(75 \%)$ benefited from endobronchial brachytherapy as their only or initial therapeutic procedure.

\section{Therapeutic indications of high dose rate brachytherapy}

The patient population was divided into four groups depending upon the primary indication for endobronchial brachytherapy. Group A consisted of 22 previously untreated patients $(12 \%)$ who were medically inoperable and presented with small endobronchial tumour strictly limited to the bronchial lumen. Group B consisted of 36 patients $(19 \%)$ presenting with acute respiratory distress due to life-threatening obstruction of one of the main bronchi and requiring emergency obstruction relief prior to any other therapy. Groups C and D $(n=131,69 \%)$ were previously treated patients. Group C consisted of those patients with residual endobronchial tumour $(n=44,23 \%)$ after full-dose external beam radiotherapy or concurrent chemoradiation therapy given with curative intent. In Group D, 87 patients presented with a late endobronchial recurrence following initial therapy with surgery and/or radiotherapy.

\section{Methods}

All patients were treated by the same physician (MT) using a MicroSelectron ${ }^{\circledR}$ (ODELFT $<$ The Netherlands) high dose rate afterloading device with an iridium- 192 source. Prior to each brachytherapy course, all patients had a thorough bronchoscopic examination, and the lesions to be treated were re-evaluated both in terms of anatomical location and extent. The extrabronchial component of the disease was evaluated by computed tomography (CT) scan and findings were correlated with the amount of endobronchial tumour. Depending on the amount, extrabronchial disease was categorized as follows: limited (25$30 \%)$; moderate (30-50\%); and major ( $>50 \%)$. After proper visualization of the target lesion, catheters were passed down the suction channel of the fibreoptic bronchoscope using one, two or three soft applicators of $1.7 \mathrm{~mm}$ diameter. Each catheter was advanced in the bronchial lumen as distally as technically feasible and was then attached to the nostril after withdrawal of the fibreoptic bronchoscope. Securing the catheter in such a way presented the advantage of locking in the distal bronchial tree, thereby avoiding any risk of dislodgement during patient transportation and treatment. Furthermore, this technique allowed optimization of the curvature of the catheter alongside the lesions to be treated. The stopping locations of the sources were determined after introduction of metal dummy sources into the empty catheters, and were chosen to provide a radiation segment that would encompass the endobronchial tumour with a minimum margin of $2 \mathrm{~cm}$, both proximally and distally. Their position was checked by anterio-posterior (AP) and lateral chest radiographs. The volume to be irradiated, the dose to be provided and the depth of the treatment area were defined, and information was transmitted to the dosimetry computer for calculations of isodose curves. The dwell times at each stopping location were then selected in a way that would avoid over-irradiation at crossing points of the catheters while providing a uniform dose distribution to the target volume. The catheters were then connected to the MicroSelectron ${ }^{\circledR}$ afterloading device, and treatment was applied for 5-10 mins, according to the preprogrammed dwell times.

The radiation dose of the iridium-192 seed was prescribed at $10 \mathrm{~mm}$ from the source axis. The initial 35 patients $(18 \%)$ received three $10 \mathrm{~Gy}$ fractions at 2 week intervals. The following 99 patients $(52 \%)$ received four 8 Gy fractions at weekly intervals, considering the good tolerance and excellent feasibility of the initial brachytherapy procedure, and in order to minimize the acute and late side-effects according to radiobiological data. Treatment modalities were customized for the remainder of the patients $(n=55,29 \%)$ according to indication for high dose rate endobronchial brachytherapy and to prior irradiation doses (table 2). In this latter group, the vast majority of the patients $(91 \%)$ were treated exclusively with endobronchial brachytherapy. Over three quarters of the patients $(77 \%)$ were given three or four consecutive sessions, 35 had only one or two courses of brachytherapy and nine had five or six treatments.

Fibreoptic bronchoscopy was performed 1 month after completion of therapy, to evaluate the endobronchial response. It was then repeated every 3 months with biopsy at the initial tumour site. Toxicity was graded according to the score of Speiser and Spratzing [2] and was adapted 
Table 2. - High-dose rate endobronchial brachytherapy protocols according to indications for treatment

\begin{tabular}{|c|c|c|c|c|}
\hline $\begin{array}{l}\text { Study } \\
\text { group }\end{array}$ & $\begin{array}{c}\text { Subjects } \\
\mathrm{n}\end{array}$ & $\begin{array}{l}\text { Dose per } \\
\text { fraction } \\
\text { Gy }\end{array}$ & $\begin{array}{c}\text { Courses } \\
n\end{array}$ & $\begin{array}{l}\text { Intervals } \\
\text { between } \\
\text { courses }\end{array}$ \\
\hline A & $\begin{array}{r}14 \\
8\end{array}$ & $\begin{array}{r}10 \\
\text { or } 8 \\
7\end{array}$ & $\begin{array}{l}3 \\
4 \\
5\end{array}$ & $\begin{array}{l}\text { Weekly } \\
\text { Weekly } \\
\text { Weekly }\end{array}$ \\
\hline B & $\begin{array}{l}25 \\
11\end{array}$ & $\begin{array}{r}10 \\
\text { or } 8 \\
6\end{array}$ & $\begin{array}{c}3 \\
4 \\
2-3\end{array}$ & $\begin{array}{l}\text { Weekly with third } \\
\text { course } 2 \text { weeks later } \\
\text { in case of inadequate } \\
\text { obstruction ratio }\end{array}$ \\
\hline $\mathrm{C}$ & $\begin{array}{r}36 \\
8\end{array}$ & $\begin{array}{r}10 \\
\text { or } 8 \\
6\end{array}$ & $\begin{array}{l}3 \\
4 \\
3\end{array}$ & Weekly \\
\hline D & 59 & $\begin{array}{r}10 \\
\text { or } 8\end{array}$ & $\begin{array}{l}3 \\
4\end{array}$ & Weekly \\
\hline $\left.\begin{array}{l}\text { D1 } \\
\text { D2 } \\
\text { D3 }\end{array}\right\}$ & 28 & $\begin{array}{l}7 \\
5 \\
6\end{array}$ & $\begin{array}{c}5 \\
6 \\
2-3\end{array}$ & $\begin{array}{l}\text { Weekly } \\
\text { Weekly } \\
\text { Weekly }\end{array}$ \\
\hline
\end{tabular}

Group A: medically inoperable patients with small strictly endobronchial tumour; Group B: acute respiratory distress due to life-threatening obstruction of one of the main bronchi, and requiring emergency obstruction relief; Group C: residual endobronchial tumour after external beam radiotherapy or concurrent chemoradiation therapy given with curative intent; Group D1: recurrence in a previously unirradiated area that can be fully encompassed in the irradiated field; Group D2: recurrence in a previously irradiated area that can be fully encompassed in the irradiation field; Group D3: massive endobronchial obstructive recurrence, palliative treatment only.

according to our own experience for radiation-induced bronchitis (table 3 ).

Table 3. - The Clinique Sainte Catherine grading system for radiation bronchitis

\begin{tabular}{ll}
\hline $\begin{array}{l}\text { Radiation } \\
\text { bronchitis grade }\end{array}$ & \multicolumn{1}{c}{ Clinical findings } \\
\hline 1 & $\begin{array}{l}\text { Mucosal inflammation without obstruction } \\
\text { Mucosal inflammation with whitish } \\
\text { discoloration and telangectasia }\end{array}$ \\
3 & $\begin{array}{l}\text { Same as grade 2, plus nonobstructive } \\
\text { pseudomembranous formation } \\
\text { Obstruction of the lumen by } \\
\text { pseudomembranes requiring debridement } \\
\text { True bronchial stenosis } \\
\text { Bronchial wall necrosis }\end{array}$ \\
\hline
\end{tabular}

Survival was calculated according to the Kaplan-Meier method. Comparisons were performed with the log-rank test.

\section{Results}

\section{Symptomatic relief and endobronchial response}

Most patients experienced major symptomatic improvement. The main presenting symptoms requiring palliative treatment were cough, dyspnoea and haemoptysis. According to the clinical opinion of the treating physician and to patients' self evaluation, complete relief of haemoptysis was achieved in $74 \%$ of cases, of dyspnoea in $54 \%$, and of cough in 54\%. Objective endobronchial response rate was $79 \%$, including $54 \%$ complete endoscopic response $(\mathrm{n}=103)$, and biopsy at the initial tumour site was negative in 79 cases. In addition, there were 46 major partial responses (24\%). Sixteen patients (8\%) had either a minor response or no change, and 21 patients $(11 \%)$ had progressive disease. As expected, the parameters found to be predictive of complete response were: the degree of endoluminal obstruction; the amount of extrabronchial disease; performance status; and the nature of the indication for endobronchial brachytherapy $(\mathrm{p}=0.0002)$. When the amount of extrabronchial disease represented less than $50 \%$ of the tumour burden, complete response rate was $62 \%$, as opposed to $44 \%$ when it exceeded $50 \%(\mathrm{p}=0.02)$. In patients with good performance status $(0-1)$, complete response rate was $76 \%$, as opposed to $35 \%$ in patients with a performance status S 2 ( $\mathrm{p}<0.0001)$. Similarly, complete response rate was $96,42,50$, and $52 \%$ in Group A, $\mathrm{B}, \mathrm{C}$ and D patients, respectively. Complete endobronchial response rate was significantly higher in Group A patients than in any of the other three groups $(\mathrm{p}=0.0005)$, and it was associated with a significantly higher rate of negative biopsies at the initial tumour site $(71 \%)$.

\section{Survival}

With a median follow-up of 32 months (range, 5-68 months), median survival was 7 months (fig. 1). Thirty three patients $(18 \%)$ had a local recurrence and $41(22 \%)$ developed distant metastasis. Among local recurrences, nine were strictly limited to the bronchial lumen, 13 were exclusively extrabronchial, and 10 were both endo- and extrabronchial. The majority of the metastases were to the brain $(n=20), 15$ of them being isolated. Other metastatic sites included bone $(n=14)$, and liver $(n=12)$. At the time of this evaluation, 32 patients were alive, including 19 patients in complete remission, as defined by complete endoscopic response and negative biopsy at the initial tumour site. One hundred and fifteen patients had died of their disease, 25 from intercurrent disease, including 14 deaths from cardiovascular disease and 14 from treat-

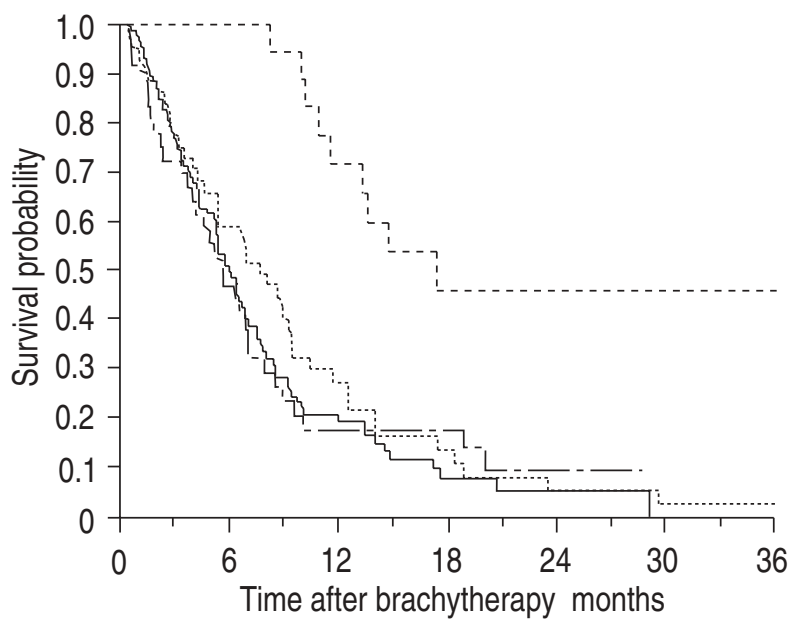

Fig. 1. - Overall survival according to indication for endobronchial brachytherapy. - - - : Group A $(n=22) ;--1$ : Group B $(n=36) ; \cdots \cdots \cdots \cdots$ : Group C ( $\mathrm{n}=44)$; — : Group D $(\mathrm{n}=87)$. 
ment-related toxicity. Actuarial overall survival was calculated from the time of endobronchial brachytherapy and was $58 \%$ at 6 months, $27 \%$ at 12 months, and $10 \%$ at 24 months. Only four patients (18\%) in Group A had a recurrence, including one case of isolated local recurrence, two cases of local and metastatic recurrence and one case of isolated metastatic disease. Overall survival in Group A was $71 \%$ at 12 months, and $46 \%$ at 24 and 30 months, with a median survival of 17 months. Clearly, survival was significantly better in this subgroup of patients $(\mathrm{p}<$ 0.0001).

\section{Acute and delayed toxicity of endobronchial brachyther-} apy

Immediate tolerance to treatment was excellent in $95 \%$ of the cases, and catheters were never dislodged from the bronchi during the procedure. Twenty two per cent of the patients presented with asymptomatic radiation bronchitis during the course of therapy. However, 32 patients (17\%) had significant grade 3-4 delayed side-effects consisting of massive haemoptysis $(n=13)$, bronchial stenosis $(n=$ $12)$, soft tissue necrosis $(n=8)$, fistula $(n=3)$, and pneumothorax $(n=1)$. There were 14 toxicity-related deaths $(7 \%)$, including 13 fatal pulmonary haemorrhages, and one fistula. Actuarial rate of serious delayed toxicity was $16 \%$ at 6 months, $21 \%$ at 12 months, and $26 \%$ at 18 months. Mean time to developing a complication was 3.6 months for the entire group, and 7 months for Group A patients. Univariate analysis failed to identify any prognostic factor for delayed toxicity. Although differences were not statistically significant, toxicity rate was $20 \%$ with upper lobe lesions, and $16 \%$ with other anatomical locations of the tumour. Similarly, it was $19 \%$ in patients treated with 8-10 Gy fractions, $13 \%$ with lower dose per fraction, $20 \%$ in previously irradiated patients, and $12 \%$ in patients who had never received radiation therapy.

\section{Discussion}

\section{Palliative endobronchial brachytherapy}

Unlike low dose rate brachytherapy [3], high dose rate brachytherapy has been largely reported in the literature to yield higher response rates while sparing normal tissues in $90 \%$ of the cases, therefore reducing toxic side-effects [4, 5]. The present study confirms that endobronchial brachytherapy provides significant reduction in the obstruction score, with an approximately $80 \%$ rate of subjective and objective improvement. These results compare favourably with the data published by several other investigators [1, 6-8]. In the large series by Gollins et al. [4], in which 406 patients were treated with high dose rate intraluminal radiotherapy, response rates were $88 \%, 62 \%$ and $60 \%$ for haemoptysis, cough and dyspnoea, respectively. This is in accordance with the response rates that we observed, i.e., $74 \%, 54 \%$ and $54 \%$ complete relief from haemoptysis. cough and dyspnoea, respectively. It is important to note that haemoptysis was the first symptom to disappear, while there was a delay of 10-15 days before dyspnoea was relieved. Endobronchial complete response rates were significantly correlated with the amount of extrabronchial disease $(62 \%$ when it was less than $50 \%$, versus $44 \%$ when it exceeded 50\%). The present data are difficult to compare with other reports in the literature since some authors have considered the presence of extensive extrabronchial disease to be a contra-indication to endobronchial brachytherapy, while others have enrolled such patients in their trials [5, 9]. SuH et al. [10] concluded in their study that endobronchial brachytherapy was an efficient procedure in relieving symptoms when it could be associated with external beam radiotherapy in patients presenting with endobronchial obstruction and a large extrabronchial component. However, it is difficult to deduce the respective effectiveness of each treatment modality from this study. In the palliative setting, it seems appropriate to limit the number of endobronchial brachytherapy courses in order to respect the quality of life of the patients while providing rapid symptomatic relief. Our current approach is to deliver one or two $6 \mathrm{~Gy}$ fractions at $10 \mathrm{~mm}$ from the source axis in each of the catheters.

\section{Endobronchial brachytherapy with curative intent}

From the start, endobronchial brachytherapy was regarded as a procedure that could be performed with curative intent in combination with external beam radiotherapy in the treatment of lung cancer $[1,7,11]$. However, these studies were inconclusive about the role of associated brachytherapy in prolonging overall survival.

In the present study, 40 patients received endobronchial brachytherapy for residual endobronchial tumour after standard thoracic irradiation. Although their prognosis was reportedly poor, it is important to note that all these patients had failed initial full-dose irradiation, and therefore could not be representative of the potentially curative benefit of combined modality radiation therapy.

SPEISER and SPRatLing [5] have proposed to boost standard external thoracic irradiation to $60 \mathrm{~Gy}$ in 30 fractions with endobronchial brachytherapy in patients with nonmetastatic T1-3, N0-3 bronchogenic carcinoma. However, no benefit in either local control or survival was demonstrated using this approach as compared with external radiotherapy alone. In a small study published in 1992 by VAN BODEGON et al. [12], selected patients were treated with external beam radiotherapy to 46 Gy and three 6 Gy courses of endobronchial brachytherapy delivered at 10 $\mathrm{mm}$ from the source. Median survival had not been reached at the time of publication, suggesting the potential benefit of endobronchial boosting in terms of local control. These results have been confirmed in a recent randomized trial by HuBER et al. [13] comparing the outcome of patients treated with external beam radiotherapy with or without associated endobronchial brachytherapy. Endobronchial treatment consisted of two 4.8 Gy courses at 10 $\mathrm{mm}$ from the source axis, delivered prior to and following external radiotherapy. Local control was significantly higher in the brachytherapy arm, but there was no difference in long-term survival between the two groups.

In highly selected patients, endobronchial brachytherapy has been used with curative intent as the sole therapeutic modality. These patients had well-circumscribed noninvasive tumours limited to the bronchial wall and were usually medically inoperable. In our experience, local control rate was $82 \%$ and median survival was 17.4 
months in this selected group of patients. TRÉDANIEL et al. [14] reported a study on 29 patients who were treated with six courses of endobronchial brachytherapy at a dose of 7 Gy per fraction and at $10 \mathrm{~mm}$ from the source axis. Twenty five patients were evaluable. There were $21 \mathrm{com}-$ plete endobronchial responses and 18 negative biopsies at the initial tumour site. Median survival exceeded 26.5 months for patients with complete pathological response. Similarly, ARDIET et al. [15] have reported encouraging results in the same clinical setting. Twenty eight medically inoperable patients with an endobronchial tumour of less than $1 \mathrm{~cm}$ in diameter and with no extrabronchial disease, as assessed by CT scan, received three to five 7 Gy fractions at $10 \mathrm{~mm}$ from the source axis. Local control was excellent, with $84 \%$ complete endobronchial and pathological response rate. Complications occurred in $14 \%$ of the cases including one fatal pulmonary haemorrhage and four cases of severe radiation-induced bronchitis. Therefore, it is legitimate to conclude from these studies that endobronchial brachytherapy has a definite curative potential in this setting.

Other authors have proposed to combine limited-field external radiotherapy with endobronchial brachytherapy. YoкоYама and SAIKo [16] have treated 40 patients with centrally located early-stage lung cancer with combined external and endobronchial irradiation. Tumours were $0.5-2 \mathrm{~cm}$ in diameter and chest radiograph was normal. Radiotherapy consisted of external irradiation at 40 Gy combined with twice-weekly endobronchial brachytherapy at 5 Gy per fraction to a total dose of 25 Gy. With a follow-up of 1-40 months, 38 patients were still free of disease. The authors concluded that combined endobronchial brachytherapy and external radiotherapy were superior to external radiotherapy alone.

\section{Delayed toxicity of endobronchial brachytherapy}

By definition, delayed toxicities of endobronchial brachytherapy are complications occurring 2 months or more after completion of treatment. Adequate assessment of these complications is, as a rule, difficult due to the heterogeneity of the patient populations, the diversity of the therapeutic protocols, the problems involved in establishing the differential diagnosis between true complications and progressive local disease, the subjectivity of evaluation criteria and the substantial proportion of early diseaserelated deaths. The picture is dominated by radiationinduced bronchitis (table 4) and includes stenosis, soft tissue necrosis, fistula and haemorrhages, the mechanisms of the latter being particularly complex.

In the present study, the incidence of symptomatic radiation bronchitis was $6.3 \%$. Although not mentioned in the

Table 4. - Incidence of radiation bronchitis after endobronchial brachytherapy

\begin{tabular}{lrccc}
\hline First author & Patients & \multicolumn{2}{c}{ Treatment schedule } & $\begin{array}{c}\text { Radiation } \\
\text { [Reference] }\end{array}$ \\
\cline { 3 - 4 } & $\mathrm{n}$ & Dose Gy & Courses n & $\%$ \\
\hline BURT [17] & 50 & $15-20$ & 1 & 2 \\
SPEISER [5] & 141 & $7.5-10$ & 1 & 4 \\
BEDWINEK [18] & 38 & 6 & 3 & 0 \\
COTTER [11] & 65 & $2.7-10$ & $2-4$ & 2 \\
TRÉDANIEL [14] & 49 & 7 & 4 & 0 \\
\hline
\end{tabular}

study published by BEDwinek et al. [18], it was reported to occur in $4 \%$ of cases by Speiser and Spratuing [2]. The authors proposed the following toxicity scale for grading radiation bronchitis: Grade 1 required no intervention and consisted of mild asymptomatic mucosal inflammation with partial whitish circumferential membrane and absence of obstruction of the bronchial lumen; Grade 2 consisted of moderate obstruction of the bronchial lumen by a thicker complete white circumferential membrane causing cough and/or other obstructive symptoms, and requiring local intervention or medical treatment; and Grade 3 consisted of severe local inflammation associated with marked pseudomembranous formation and mild fibrosis of the bronchial wall, repeated de-obstructing procedures being necessary and consisting of local debridement or other interventions to re-establish the full lumen of the airway; and Grade 4 was characterized by major fibrosis with circumferential stenosis of the lumen requiring laser photoresection and balloon or bouge dilatation, with or without stent placement. The Grade 4 lesions tended to worsen with time. The time to developing radiation bronchitis was 16 weeks for grade 1 lesions and 54 weeks for grade 4 lesions. However, this scoring system fails to differentiate accumulation of pseudomembranes from true stenosis by fibrotic irreversible narrowing of the bronchial lumen. In addition, it does not take into account transparietal fistulae formation.

Fistulae are secondary to bronchial wall necrosis and can be either minimal or massive. Early fistulae are usually the result of massive tumour shrinkage, while lateoccurring fistulae represent the ultimate phase of Grade 4 radiation bronchitis. Table 3 summarizes the radiation bronchitis grading system that we use in our institution.

Pulmonary haemorrhages can develop either early or late after completion of endobronchial brachytherapy and are usually fatal. There is considerable variation in their reported incidence, ranging 1-32\% (table 5). Furthermore, their mechanism has given rise to many hypotheses due to difficulties in assessing the respective roles of the tumour itself and of true treatment toxicity. Clearly, when palliative endobronchial brachytherapy is indicated in the treatment of extensive endobronchial lesions eroding through the bronchial wall in patients with mediastinal lymph node involvement and large extrabronchial tumour burden, tumour progression by itself is sufficient to explain pulmonary haemorrhages. Furthermore, massive haemoptysis is

Table 5. - Incidence of radiation-induced haemorrhage

\begin{tabular}{|c|c|c|c|c|}
\hline \multirow{2}{*}{$\begin{array}{l}\text { First author } \\
\text { [Reference] }\end{array}$} & \multirow{2}{*}{$\begin{array}{l}\text { Patients } \\
\text { n }\end{array}$} & \multicolumn{2}{|c|}{ Treatment schedule } & \multirow{2}{*}{$\begin{array}{c}\text { Haemorrhage } \\
\%\end{array}$} \\
\hline & & Dose Gy & Courses $\mathrm{n}$ & \\
\hline BEDWINEK [18] & 38 & 6 & 3 & 32 \\
\hline GauWITZ [19] & 24 & 15 & 2 & 4 \\
\hline МАСНА [20] & 56 & 7.5 & 3 & 7 \\
\hline Мента [3] & 31 & 4 & 3 & 3 \\
\hline SuTEDJA [21] & 31 & 10 & $1-3$ & 32 \\
\hline SPEISER [5] & 295 & $7.5-10$ & 3 & 7 \\
\hline BuRT [17] & 50 & $15-20$ & 1 & 1 \\
\hline COTTER [11] & 65 & $2.7-10$ & IDR & 1.5 \\
\hline Trédaniel [14] & 49 & 7 & 4 & 4 \\
\hline Goluns [4] & 406 & $15-20$ & 1 & 7.9 \\
\hline Sтоuт [22] & 100 & $15-20$ & 1 & 4 \\
\hline
\end{tabular}

IDR: intermediate dose rate. 
a well-known feature in the natural history of lung cancer and is the cause of death in a number of cases. Other factors, such as prior external irradiation and anatomical location of the tumour, appear to increase the risk of fatal pulmonary haemorrhage. This is particularly true of lesions located in the upper lobe which come in close contact with the large pulmonary vessels. In this setting, pulmonary haemorrhages cannot be attributed solely to complications of endobronchial brachytherapy. However, the pathophysiology of haemorrhages following endobronchial brachytherapy remains unclear. BEDWINEK et al. [18] have speculated upon three possible mechanisms. Firstly, endobronchial brachytherapy, while decreasing the risk of death from neoplastic airway obstruction, could increase the relative risk of death from haemorrhage by peripheral tumour growth and erosion into an adjacent large pulmonary vessel. Secondly, prior external beam irradiation could be responsible for a weakening of the adjacent bronchial wall, and superimposed brachytherapy in that area would bring the total dose of irradiation to a level that would cause radiation necrosis. Finally, the tumour itself could have created a bronchial-arterial fistula that would be uncovered at the time of brachytherapy-induced tumour shrinkage, resulting in fatal haemorrhage $[18,21]$. In our experience, the incidence of this complication was $7 \%$, i.e., comparable to the $7 \%$ incidence reported by SpeISER and Spratuing [5]. Although probably overestimating the rate of this complication, we have assumed in publishing our results that all cases of pulmonary haemorrhages were the direct consequence of endobronchial brachytherapy. In the study reported by МАснА et al. [20], analysis of the causes of toxic death following endobronchial laser photoresection demonstrated a significantly higher incidence of fatal hae-morrhage following this procedure than after external radiotherapy ( $34 \%$ versus $7 \%$ ).

Clearly, the quality of the adjacent bronchial mucosa is a prognostic factor for developing radiation bronchitis. When patients are treated with endobronchial brachytherapy for small noninvasive tumours surrounded by a healthy mucosa, they are less likely to develop this complication than when treatment is applied to large tumours that have destroyed the normal architecture of the bronchial wall. Lastly, there is a well-established relationship between total previous radiation dose and incidence of radiation bronchitis [23], with a very low rate of complications occurring when the dose per fraction does not exceed $5 \mathrm{~Gy}$. In summary, the rate of endobronchial brachytherapy-induced complications ranges $15-18 \%$. Therefore, it is of major importance to calculate precisely the cumulated dose of external and endobronchial irradiation in designing future endobronchial brachytherapy trials. To date, many questions remain unanswered. Is it necessary to adjust the total radiation dose, the dose per fraction and the interval between sessions in previously treated patients in order to avoid excessive toxicity? Should upper lobe lesions be managed differently? The current tendency is to customize treatment for each individual patient rather than routinely applying the same protocol in every clinical setting. It is technically feasible to protect the bronchial mucosa from the radioactive source by increasing the distance between the source and the mucosa, thereby limiting the total length of the boosted area, and subsequently the incidence of delayed toxicity. Only prospective, and possi- bly randomized, studies will allow the treatment modalities in endobronchial brachytherapy to be optimized.

\section{Conclusion}

High dose rate endobronchial brachytherapy is a use-ful tool in the palliative treatment of obstructive lung carcinoma and presents the advantage of being of short duration in a population of patients with limited life expectancy. It provides substantial improvement in quality of life by rapidly and efficiently relieving the symptoms of bronchial obstruction. Limiting the number of sessions could further improve patients' comfort. When used with curative intent, the role of endobronchial boosting in association with external beam radiotherapy remains to be determined, and there is considerable interest in using this procedure as the sole treatment method in medically inoperable patients with small noninvasive endobronchial tumours. Additional studies are warranted in order to determine the long-term impact of endobronchial brachytherapy on survival and to define the optimal therapeutic strategy.

\section{References}

1. Kohek PH, Pakisch B, Glanzer H. Intraluminal irradiation in the treatment of malignant airway obstruction. Eur $J$ Surg Oncol 1994; 20: 674-680.

2. Speiser BL, Spratling L. Radiation bronchitis and stenosis secondary to high dose rate endobronchial irradiation. Int J Radiat Oncol Biol Phys 1993; 25: 589-597.

3. Mehta M, Petereit D, Chosy L, et al. Sequential comparison of low dose rate and hyperfractionated high dose rate endobronchial radiation for malignant airway occlusion. Int J Radiol Oncol Biol Phys 1992; 23: 133-139.

4. Gollins S, Burt PA, Barber PV, Stout R. High dose rate intraluminal radiotherapy for carcinoma of the bronchus: outcome of treatment in 406 patients. Radiother Oncol 1994; 33: 31-40.

5. Speiser BL, Spratling L. Remote afterloading brachytherapy for the local control of endobronchial carcinoma. Int J Radiol Oncol Biol Phys 1993; 24: 579-587.

6. Jacobson MJ, LoCicero J. Endobronchial treatment of lung carcinoma. Chest 1991; 100: 838-841.

7. Macha HN, Walhers B. Intraluminal high-dose rate irradiation of obstructing bronchial tumors: techniques, clinical management and results. Proceedings of the Fifth International HDR Remote Afterloading Conference 1990, April 29-May 2, Norfolk, VA, USA, 37.

8. Roach M, Leidholdt EM Jr, Tatera BS, Joseph J. Endobronchial radiation therapy (EBRT) in the management of lung cancer. Int J Radiol Oncol Biol Phys 1990; 18: 1449-1454.

9. Miller JI Jr, Phillips TW. Neodymium-YAG laser and brachytherapy in the management of inoperable bronchogenic carcinoma. Ann Thorac Surg 1990; 50: 190-195.

10. Suh JH, Dass KK, Mehta AC, et al. Use of endobronchial radiation therapy or endobronchial brachytherapy and Nd-YAG laser for management of malignant airway obstruction. American Radium Society 75th Annual Meeting 1993; April 24-28, Aruba, pp. 23-24.

11. Cotter GW, Herbert DE, Ellingwood KE. Inoperable endobronchial obstructing endobronchial carcinoma trea- 
ted with combined endobronchial and external beam irradiation. South Med J 1991; 84: 562-565.

12. Van Bodegon PC, Becker HD, Fritz P, et al. Long-term palliation of advanced tracheobronchial tumors by HDR brachytherapy in the interdisciplinary concept. Eur Respir J 1992; 5: Suppl. 15, 337-338.

13. Huber RM, Fischer R, Hautmann H, Pöllinger B, Haussinger $\mathrm{K}$, Wendt $\mathrm{T}$. Does additional brachytherapy improve the effect of external irradiation? A prospective randomized study in central lung tumors. Eur Respir J 1996; 9: Suppl. 23, 10s.

14. Trédaniel J, Hennequin C, Zalcman G, et al. Prolonged survival after high-dose rate endobronchial radiation for malignant airway obstruction. Chest 1994; 105: 767772 .

15. Ardiet JM, Perol M, Mornex F, et al. Curative irradiation of limited endobronchial epidermoid carcinomas with HDR endolumenal brachytherapy. A pilot study. Ann Oncol 1992; 3 (Suppl. 5): 38.

16. Yokoyama A, Saiko M. A phase II study of combined endobronchial brachytherapy and external radiotherapy for centrally located early stage lung cancer. Proc Am Soc Clin Oncol 1995; 14: A1069.

17. Burt PA, O'Driscoll BR, Notley HM, Barber PV, Stout R. Intraluminal irradiation for the palliation of lung cancer with the high dose MicroSelectron. Thorax 1990; 45: 765-768.

18. Bedwinek J, Petty A, Bruton C, Sofield J, Lee L. The use of high dose rate endobronchial brachytherapy to palliate symptomatic endobronchial recurrence of previously irradiated bronchogenic carcinoma. Int J Radiol Oncol Biol Phys 1992; 22: 23-30.

19. Gauwitz M, Ellerbroek N, Komaki R, et al. High dose endobronchial irradiation in recurrent bronchogenic carcinoma. Int J Radiol Oncol Biol Phys 1992; 23: 397-400.

20. Macha HS, Becker KO, Kemmer HP. Patterns of failure and survival in endobronchial laser resection. A matched pair study. Chest 1994; 105: 1668-1672.

21. Sutedja G, Baris G, Schaake-Koning C, van Zandwijk N High dose rate brachytherapy in patients with local recurrences after radiotherapy of non small cell lung cancer. Int J Radiol Oncol Biol Phys 1992; 24: 551-553.

22. Stout R, Barber PV, Burt PA, O'Driscoll BR, Notley M. Intraluminal brachytherapy in bronchial carcinoma. $\mathrm{Br} \mathrm{J}$ Radiol 1990; 63 (Suppl. Congress): 16.

23. Fuwa N, Morita K, Ito Y, Shouji K, Koyama K, Kato E. Treatment results of endobronchial carcinoma with a new applicator of intraluminal irradiation using Ir-192 thin wires. International Congress of radiation Oncology 1993; June 21-25, Kyoto, Japan, p. 375. 